\title{
Quality inspection and prediction of the comfort of fabrics finished with functional polymers
}

\author{
DOI: $10.35530 / I T .071 .04 .1734$
}

\section{ABSTRACT - REZUMAT}

Quality inspection and prediction of the comfort of fabrics finished with functional polymers

Textile's primary hand (HV) and total hand values (THV) are very important parameters and are used to identify the quality of clothing comfort. This paper aims to predict the HV and THV of the fabrics finished with functional polymers by applying Kawabata's translation equations. The mechanical properties were achieved using Kawabata's fabric evaluation system (KES-F) and the inference/interpretation was drawn. Then, HV and THV predictions were performed by applying Kawabata's translation equations of the KN-101 and KN-301 series. The KES-F result confirmed that it is possible to observe the operative finishing effect on the mechanical properties of fabrics. The prediction results show that the total quality comfort of the functional fabrics could able be estimated by the equation developed by Kawabata; the calculated errors ( 0.66) were within the range of the standard deviations ( 0.78) of the samples between the predicted and ranked THV. The experimental and the calculated primary hand values showed strong correlation coefficients up to $\sim 0.98$ which is significant at 0.001 confidence levels. As actual functional fabrics with various surface properties were provided to estimate their tactile comfort via the equations, the result verified that the equation is reliable for the tactile comfort evaluation and grading.

Keywords: translation equations, THV, low-stress mechanical properties, tactile comfort, polymer

\section{Evaluarea calității și predicția confortului senzorial în cazul purtării materialelor textile finisate cu polimeri funcționali}

Tușeul materialelor textile (HV) și indicele total de tușeu (THV) sunt parametri foarte importanți pentru evaluarea calității produselor de îmbrăcăminte din punctul de vedere al confortului la purtare. Lucrarea are ca scop propunerea unei metodologii de predicție a HV și THV pentru materiale textile tratate cu polimeri funcționali, prin utilizarea ecuațiilor tranzitorii Kawabata. Proprietățile mecanice ale materialelor textile au fost determinate prin utilizarea unui sistem Kawabata (KES-F) și s-a realizat prelucrarea/interpretarea acestora. Predicția valorilor HV și THV a fost realizată prin utilizarea ecuațiilor tranzitorii Kawabata, seriile KN-101 și KN-301. Rezultatele testelor efectuate pe KES-F au evidențiat influența tratamentelor de finisare asupra proprietăților mecanice ale materialelor textile analizate. Rezultatele predicției au demonstrat că asigurarea confortului la purtarea materialelor funcționale poate fi estimată prin ecuațiile dezvoltate de Kawabata; eroarea calculată $(\sim 0,66)$ se încadrează în intervalul abaterii standard $(\sim 0,78)$ pentru materialele analizate, între valoarea previzionată și cea determinată a THV. Corelația dintre valoarea determinată experimental a indicelui de tușeu (HV) și cea calculată este puternică, demonstrată prin valoarea coeficientului de corelație de aproximativ 0,98, semnificativ pentru un nivel de încredere de 0,001. Rezultatele obținute pentru materialele textile cu finisări funcționale analizate arată că ecuațiile utilizate pentru modelare sunt adecvate pentru evaluarea și ierarhizarea confortului senzorial.

Cuvinte-cheie: ecuații tranzitorii, THV, solicitări mecanice de intensitate mică, confort senzorial, polimer

\section{INTRODUCTION}

Recent research progresses in the wearable e-textile applications have witnessed exciting improvement of the use of the functional fabrics finished with conductive polymers such as wearable electronics textiles [1], textile-based strain sensors [2-4], wearable selfpowered textile electronics [5], electrically-conducting textiles [6], wearable and flexible electroluminescence devices [7]. However, the assessment of these electronic textiles with respect to comfort aspect has little or no exploration has been performed. The comfort issue could be inspected by estimating the primary and the total hand values of the wearable textiles from its mechanical properties [8]. In predicting the HV and THV of the materials, it's presumably to assess the tactile comfort of the textile product.

Tactile/sensorial comfort is the combined results of the interaction between the wearer's skin, the clothing materials, and the environment [9]. It is one of the straightforward performance parameters for the inspection of comfort quality of clothes intended for wearing. Wearable e-textiles have a direct contact with the skin of the user and hence the tactile comfort of these fabrics shall be investigated. Tactile comfort has a strong association with the mechanical properties of clothing goods measured under low-region conditions [10-14]. In addition, the subjectively measured, quality index assessed by human experts, and 
the objectively measured mechanical properties have been applied to optimize the fabric properties as mentioned in [15]. Linen fabrics subjected to various finishing as well as blended with other fibers have been investigated for its ease using KES-F [16]. However, standard fabrics touch the whole body parts while functional fabrics may or may not touch the whole body parts. That is why this paper intended to find if there is mandatory or is there any difference between the standard and functional fabrics comfortable property prediction when applying the same equations.

The KES is the primary system that does not only foresee the human sensory perception but also figuring out the sensitivity of the tactile properties of the fabrics. In the 1980s, Kawabata and his co-workers [17] established the Kawabata's evaluation system (KES-F), a sophisticated and reliable tool to measure the low-stress mechanical properties of (tensile, shearing, bending, compression, thickness, weight, surface, and frictional) various kinds of fabrics. The KES system that was initially designed for the objective evaluation of textile-based goods under low-load regions enables a precise measurement which is sufficient for the quality inspection of textile-based materials and further used to the quality assurance and design development purpose. Kawabata and his coworkers derived translations of equations capable to calculate the quality of wearable textiles in terms of primary hand and total quality index including men's suiting fabrics. Some researchers have been used the translation equations (man's winter suit) developed by Kawabata for the prediction of handle values of various kinds of clothing materials such as futon cloth [18], terry fabrics [19], blankets [20], non-woven [21], and toilet papers [22]; with slight adjustments and they found promising outcomes. This encourages the idea of deriving the quality of fabrics finished with functional polymers to use the Kawabata's translation equations that have been applied to predict the quality of men's winter suiting fabrics.

In this paper, Kawabata translation equations (KN-101 series) were applied to predict the primary hand and the total hand value of the functional fabrics. The lowstress mechanical properties were inferred and used as input parameters to predict the hand factors. First, the mechanical properties were converted into the primary hand values (HV) using the $\mathrm{KN}-101$ equation, then the tactile quality of the functional fabric was derived from the HV, using the equation $\mathrm{KN}-301$. The prediction was performed based on the assumption that functional fabrics have the comparable sensorial perception to that of men's winter suit. With the clue provided by the data chart and the prediction results, it could be possible to attain the persuasive connection and communication between various stakeholders such as researchers, quality controllers, manufacturers, and traders of the functional and smart textile industries by giving specified quality parameters and specifications of the quality of smart fabric production.

\section{MATERIALS AND METHODS}

\section{Preparations of functional fabrics}

A woven polyester fabric that have a weight of 158 $\mathrm{g} / \mathrm{m}^{2}, 30$ ends $\mathrm{cm}^{-1}, 22$ picks $\mathrm{cm}^{-1}$, and scoured and heat-set by the supplier (Almedahl-Kinna AB, Sweden) as the substrate (sample 7) used to produce five different functional fabrics as follows:

The photochromic sample (sample 1) was prepared using inkjet printing tools (a Sapphire QS 10 print head from Fujifilm Dimatix, USA). A commercial heterocyclic Spiro-compound (Reversacol Ruby Red) photochromic dye from Vivimed Labs with a concentration of $2.5 \mathrm{~g} / \mathrm{l}$; a varnish which entails dipropylene glycol diacrylate monomer, amine modified polyether acrylate oligomers (Ebecryl 81) from Allnex SA/NV, Belgium and a photo-initiator (Genocure TPO-L) from Rahn AG, Switzerland were used to prepare the inkjet printing to achieve a surface tension of $30 \mathrm{mN} / \mathrm{m}$ and a viscosity of $10.6 \mathrm{mPa} \cdot \mathrm{s}$ at $20^{\circ} \mathrm{C}$ and $10000 \mathrm{~s}^{-1}$. After preparing the printing solution, printing was carried out at a resolution of 300 dpi with a print head temperature of $35^{\circ} \mathrm{C}$ for 10 layers and the recipe was prepared as per [23]. Finally, the sample was cured using UV-LED light at $30 \%$ intensity. The final sample had a CIE DE (color space) value of $2.74 \pm 0.583$.

Conductive sample (sample 4) was prepared using similar inkjet printing machine and the same printing parameters as of sample 1 . The poly (3, 4-ethylenedioxythiphene): poly (styrene sulfonate) (PEDOT-PSS) - a conductive polymer (Heraeus $\mathrm{GmbH}$, Germany) with a concentration of $1.3 \%$ by weight; and a PSS to PEDOT ratio of 2:5 was used as the conductive agent. A glycerol (from Sigma Aldrich) in deionized water $(6: 4 \mathrm{w} / \mathrm{w})$ was used to optimize the rheology of inkjet inks. The final ink had a rheology of $29 \mathrm{mN} / \mathrm{m}$ and viscosity of $\sim 14 \mathrm{mPa} \cdot \mathrm{s}$ at $20^{\circ} \mathrm{C}$ and $1000 \mathrm{~s}^{-1}$. The printing process was performed for 50 layers. Then, the sample was dried at $100^{\circ} \mathrm{C}$ for 15 minutes and cured at $150^{\circ} \mathrm{C}$ for 10 minutes. The surface resistance of the sample was $0.168 \pm 0.013 \mathrm{k} \Omega \square^{-1}$. Conductive specimen (sample 5) was prepared by coating techniques using PEDOT-PSS as a conductive polymer, dimethyl sulfoxide (98\%) (DMSO) $(5 \%)$ from Sigma Aldrich as a conductive enhancer, U2101 from Alberdingk Boley with a viscosity of $\sim 100 \mathrm{cps}$ and weight of $\sim 60 \mathrm{wt} \%$ as a binder, and hydrophobically modified ethoxylated urethane symbolized by Gel L75N ( Borchers GmbH) having 48 wt\% as a rheology modifier were used to prepare the coating paste. The paste was thoroughly mixed using an overhead mechanical mixer at a speed of $800 \mathrm{rpm}$ until it became homogeneous with the naked eye. The coating was performed with a manual coating applicator with adjustable height at $200 \mu \mathrm{m}$ gap distance to the substrate materials. Finally, the sample was dried at $90^{\circ} \mathrm{C}$ for 30 minutes and cured at $150^{\circ} \mathrm{C}$ for 3 minutes. The surface resistance value was 7.98 $\pm 0.969 \Omega \square^{-1}$.

Conductive specimen (sample 6) was prepared using manual screen printing machine with a polyester mesh of size 70 . The printing was performed to-and-fro 
motion three times to bring a dark shade. The chemicals and the pre- and post-preparation techniques were similar to that of sample 5 as mentioned above. The surface resistance was $4.41 \pm 0.396 \Omega \square^{-1}$.

Thermochromic specimen (sample 9) was prepared using manual screen printing techniques with the same principle to that of sample 6 mentioned above. A Variotherm $A Q$ thermochromic ink $(5 \%)$ with an activation temperature of $32^{\circ} \mathrm{C}$ and a ChromaZone reversible based extender (binder) (95\%) from Zenit, Sweden were used to prepare the printing pastes. The sample was then cured at $170^{\circ} \mathrm{C}$ for 7 minutes to produce a sample having a color space (CIE DE) value of $54.07 \pm 2.48$.

\section{Subjective evaluation of fabrics}

Total hand value for each specimen was evaluated by ten trained panels of experts who were recruited taken into account their voluntariness and professional background. The experts were first brainstormed to be aware about tactile descriptors and ranking scales for the subjective evaluation. The subjects ranked the samples by touching and gripping the fabrics using a five-point scale; from 1 (very uncomfortable) to 5 (very comfortable). The subjects assess the sample both in blind touch and visual touch scenarios; the average was recorded. The mean scores of 10 assessors was reported as THVSub (subjective total hand value) and compared with the experimental data obtained by experimental THV (THV-KES) and calculated THV (THV-Cal) values obtained using the translation equation $\mathrm{KN}-301$. The procedures of the subjective evaluation of the specimens found in our previous work [24].

Objective evaluation of fabrics

The mechanical properties of tensile, shear, bending, compression, surface, and frictional for the functional fabrics were measured under low-load regions using tensile and shear tester (KES-F1), bending tester (KES-F2), compression tester (KES-F3), surface and friction tester (KES-F4) using an instrument called KES FB-Auto (KATO TECH CO., LTD). All the lowstress mechanical properties were measured in both the warp and the weft directions excluding the compressional property; the average was reported. The details of the mechanical properties are shown in table 1.

\section{RESULTS AND DISCUSSION}

Functional fabrics were prepared employing different functional polymers and methods in order to have diverse functionalities and physical and surface properties. Meanwhile, samples have been evaluated subjectively for its total hand values and objectively for its low-stress mechanical properties that could be further used to predict its primary and total and values using predicting equations. The overall assumption for the intended use of the functional fabrics is to use as a raw material for the production of men's winter suiting fabric. Each sub-section explained taken into account the above mentioned understanding and assumption.

\section{Effect of functional finishing using polymers on mechanical properties}

Figure 1 demonstrates 15 mechanical properties of the functional and control samples measured under low-load regions using KES-F under the test conditions used in [17]. The samples are produced using different state of the art technologies and sample 7 (control sample) is included for comparison purposes. A greater difference was found in shearing properties especially in the shear rigidity $G$ and shear hysteresis at $0.5^{\circ}$ shear angle when observed visually from

\begin{tabular}{|c|c|c|}
\hline \multicolumn{3}{|c|}{ MECHANICAL AND SURFACE PROPERTIES [17] } \\
\hline Parameters & Properties & Description of mechanical properties \\
\hline \multirow{4}{*}{ Tensile } & EMT $(\%)$ & The elongation, the strain at $500 \mathrm{gf} / \mathrm{cm}$ \\
\hline & LT & The linearity of load-extension curve \\
\hline & WT $\left(\mathrm{gf} \cdot \mathrm{cm} / \mathrm{cm}^{2}\right)$ & The tensile energy recorded per unit area \\
\hline & RT (\%) & The tensile resilience, recovery from tensile deformation \\
\hline \multirow{2}{*}{ Bending } & $B(\mathrm{gf} / \mathrm{cm} \cdot \mathrm{deg})$ & Bending rigidity, the average slope of the linear regions \\
\hline & $2 \mathrm{HB}(\mathrm{gf} \cdot \mathrm{cm} / \mathrm{cm})$ & Bending hysteresis average width at $\pm 0.5 \mathrm{~cm}^{-1}$ curvature \\
\hline \multirow{3}{*}{ Shear } & $\mathrm{G}[\mathrm{gf} / \mathrm{cm} \cdot \mathrm{deg})$ & The shear rigidity, the average slope of the linear region to $\pm 2.5^{\circ}$ shear angle \\
\hline & $2 \mathrm{HG}(\mathrm{gf} / \mathrm{cm})$ & Shear hysteresis at average width at $0.5^{\circ}$ shear angle \\
\hline & 2HG5 (gf/cm) & Shear hysteresis average widths at $5^{\circ}$ shear angle \\
\hline \multirow{3}{*}{ Compression } & LC & The linearity of Compression-thickness curve \\
\hline & $\mathrm{WC}\left(\mathrm{gf} \cdot \mathrm{cm} / \mathrm{cm}^{2}\right)$ & The compressional energy per unit area \\
\hline & $\mathrm{RC}(\%)$ & The compressional resilience; recovering ability \\
\hline \multirow{3}{*}{ Surface friction } & MIU & The coefficient of fabric surface friction \\
\hline & MMD & The mean deviation of MIU \\
\hline & $\operatorname{SMD}(\mu \mathrm{m})$ & The geometrical roughness \\
\hline
\end{tabular}




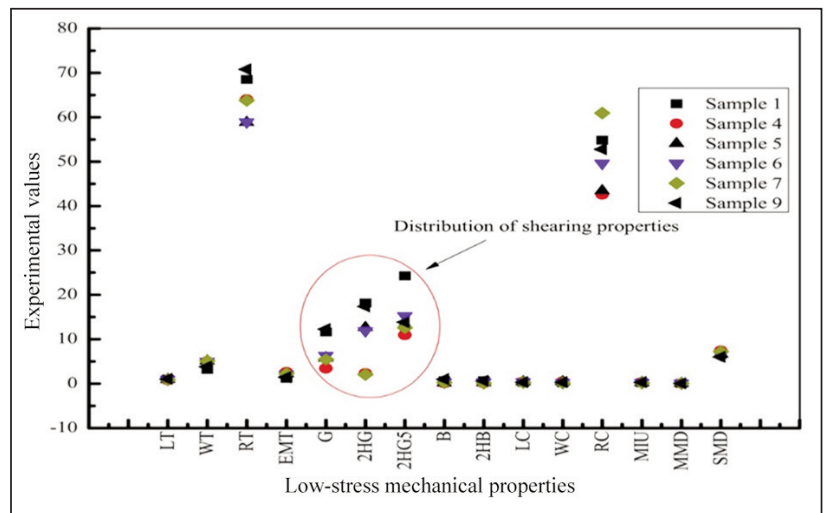

Fig. 1. Tensile, shearing, bending, compression, and surface friction properties as measured using KES-FB

the graph. Sample 9 attains rigidity $\mathrm{G}$ value of 12.25 $\mathrm{g} / \mathrm{cm} \cdot \mathrm{deg}$; more than 2 times with the control sample and more than 3.5 times to the sample with the lowest stiffness value. In addition, sample 1 achieves a bending hysteresis $2 \mathrm{HB}$ value of $0.659 \mathrm{gf} \cdot \mathrm{cm} / \mathrm{cm}$; more than 6 times with the sample having the best recoverability and more than 2.5 times than the control sample. Apparently, the inkjet-printing sample prepared using PEDOT-PSS plays a critical role in producing the best flexible and recoverable (resilient) sample. Likewise, the work of compression WC (an indication of softness obtained during sensory evaluation) and mean coefficient of friction MMD attain a difference of $\approx 60$ and $\approx 12 \%$, respectively between the most and least fabrics with compressional and frictional properties. The above piece of information indicates that the functional finishing and the use of different chemicals influence the stiffness and the softness of the samples.

On the other hand, sample 9 attains a tensile linearity value of $\sim 1.033$ (as the value came close to 1 , the sample becomes tougher and harder) which surpasses 1.2 times to that of the control sample and 1.3 to that of the sample with the least tensile linearity (sample 4). These values assured that functional finishing influences the tensile linearity of the curve only to some level. The KES evaluation results confirmed that the functional finishing using various polymers brought different and physico-sensorial perceptions that may influence the overall quality index of the wearable textiles.

\section{Interpreting the quality control chart for quality inspection}

The processability and tailorability control chart were first demonstrated by
Kawabata and his co-workers in 1980 [17]. The hand evaluation and standardization committee (HESC) introduced the data chart for considering the property of the fabric by plotting its low-stress mechanical measured by KES. For demonstration purpose, we interpret the data chart for only one functional fabric including the control sample for comparison purposes. Figure 2 illustrates the data chart for the lowstress mechanical properties of the fabrics in which the common scale is the scale normalized by the standard deviation $=(X-\bar{X}) / \sigma$. The functional fabric was produced using $1 \%$ PEDOT-PSS mixed with 6:4 $\mathrm{w} / \mathrm{w}$ ratio of glycerol in water with a resolution of 300 dpi. The polyester samples were used to produce the functional fabric as a substrate.

As shown in the figure, it is possible to figure out the clear difference between the two samples. On the other hand, the result indicates that the functional finishing drawing an alteration in the mechanical properties of the fabric which indirectly approves the change in the tactile comfort of the sample. Finishing altered the shear properties to a little extent. For example, we noted that the shearing properties $(G$, $2 \mathrm{HG}$ and 2HG5) of the functional fabrics distributed in varied level. While the other results displayed at least in the equivalent pattern. For shearing properties, before treatment, we observed a shear rigidity of G $\sim 5.49 \mathrm{~g} / \mathrm{cm} \cdot \mathrm{deg}$, shear hysteresis at $0.5^{\circ}$ shear angle of $2 \mathrm{HG} \sim 2.07 \mathrm{~g} / \mathrm{cm}$, and shear hysteresis at $5^{\circ}$ shear angle of $2 \mathrm{HG} 5 \sim 12.6 \mathrm{~g} / \mathrm{cm}$. After treatment with acidic PEDOT-PSS and glycerol using inkjet printing techniques, we noticed a basic change of shear rigidity G to $\sim 3.44 \mathrm{~g} / \mathrm{cm} \cdot \mathrm{deg}$, shear hysteresis at $0.5^{\circ}$ $2 \mathrm{HG}$ to $\sim 2.3 \mathrm{~g} / \mathrm{cm}$, and shear hysteresis at $5^{\circ} 2 \mathrm{HG} 5$ to $\sim 10.97 \mathrm{~g} / \mathrm{cm}$. This might be ascribed to the process parameters (temperature and pressure of the inkjet printing machine) and the process chemicals (water, acidic PEDOT-PSS and glycerol) might change the physical properties of the fabric during functional finishing actions. This is because PEDOTPSS treated fabrics became stiff [25] which is sup-
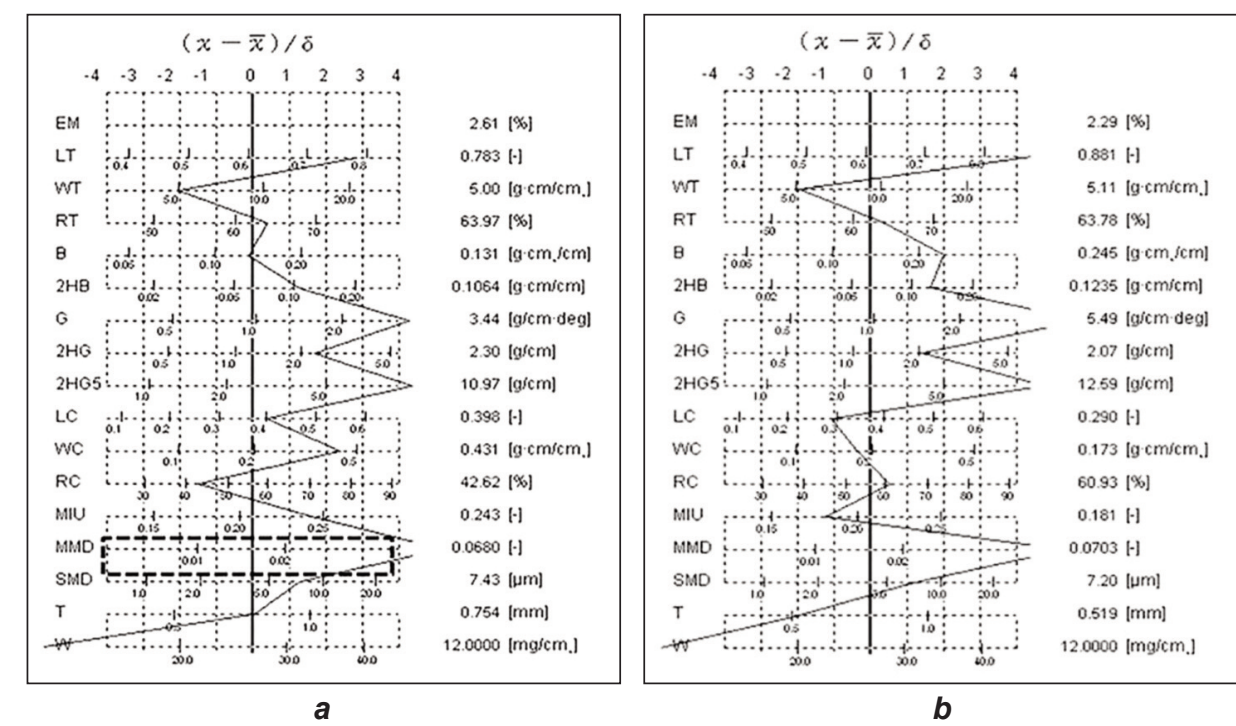

Fig. 2. Quality control chart for primary handle value of: a - functional fabric produced using inkjet printing; $b$ - polyester (control) sample 
ported as the shear rigidity reduced by $\sim 37 \%$. As the shear rigidity increased, the fabric became easily deformed. This means the stiffness is affected due to functional treatment.

In some mechanical results, only slight difference occurred to some level only when compared to other values. For instance, the key feature for the tactile comfort, the finishing effect brought only a few changes in the surface friction properties. The coefficient of friction MIU increased by only $27 \%$. Similarly, the geometrical roughness increased by $3.19 \%$. On the contrary, the mean deviation of the coefficient of friction MMD reduced by $3.27 \%$. MMD is related to the roughness and the smoothness of the surface of the fabric; the larger the MMD value means the rougher the surface is. Here, functional finishing increases the smoothness of the fabric's outer surface. This could be attributed to the functional finishing covers the protruded fibers on the surface of the fabric and hence the roughness decreased.

The overall data chart indicates that the functional finishing bringing about no severe changes in the low-stress mechanical properties and by this, it could be possible to control the quality of the fabric against the standard values. However, some values are falling off the control chart (fall on the non-control zone), then control in the finishing process is required corresponding to the run-in parameters. Otherwise, the zone within the standard deviation zone is a highquality fabric zone, in which the parameters of the high-quality fabrics.

The experimental investigation of the low-stress mechanical properties using KES also used to obtain the primary (Koshi, Numeri and Fukurami for men's winter suit) and the total hand value (THV) of the sample fabrics. Figure 3 demonstrates the primary and THV values. The experiment was performed by assuming both fabrics can be used to produce men's winter suit.

Figure 3 shows the range of primary and total hand values of the functional fabric and its substrate (control) fabric that supposed to be used to produce men's winter suiting fabrics. THV values are regarded as good when it is greater than 4 and poor when it is below 2 out of 5 points. Printing with PEDOT-PSS and glycerol yielded polyester fabrics with total hand values 2.64 (figure 3 ) which is within the range of medium value while the THV of the control fabric 1.98 is within the range of the poor grade. This could be attributed to the surface physical roughness SMD improved owing to the removal of protruding fibers during finishing. This is because the surface coating was performed using inkjet printing. Both samples showed a preferred KOSHI (stiffness). However, stiffness value reduced during finishing. The other reason could be the gap between the weft and the warp yarn occupied by finishing agents. Thus, the stiffness improved while finished. On the other hand, the NUMERI (smoothness) value is within a very modest value (below zero). This could be ascribed to smoothness subjected to be diminished with the minor

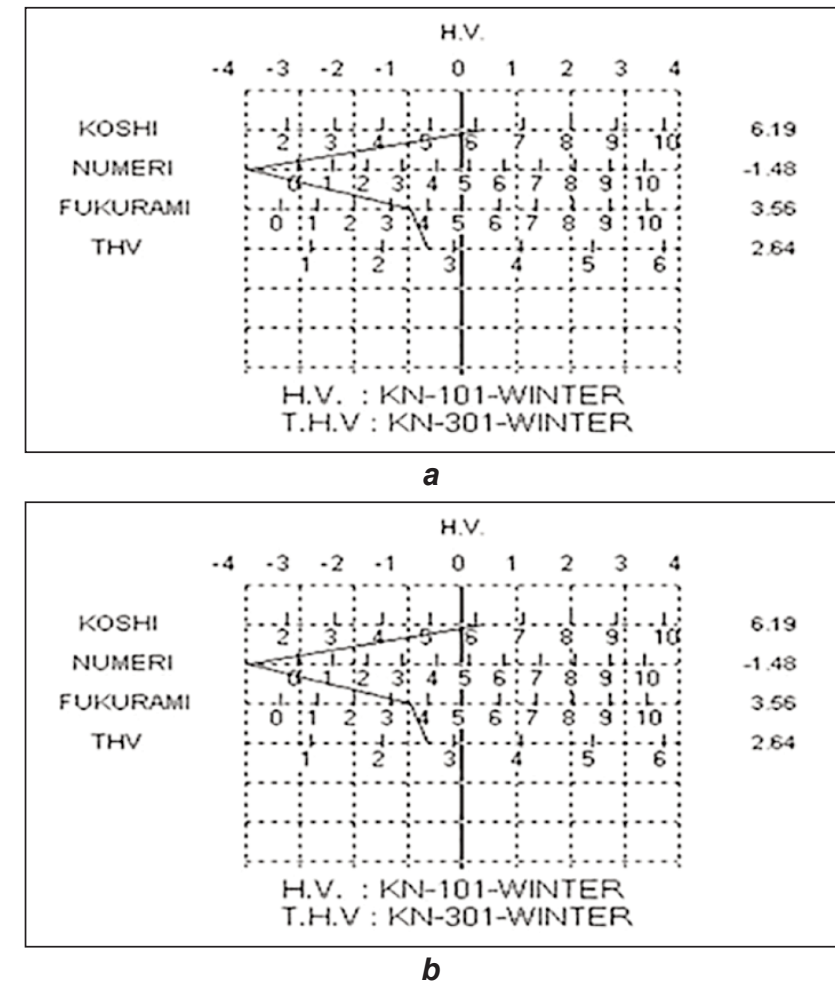

Fig. 3. Experimental values of the primary and total hand values for: $a-$ functional fabric produced using inkjet printing; $b$ - the polyester (control) fabric

variation of the frictional force. But, further investigation is needed in the functional fabric area.

\section{Predicting the primary and total hand values using equation $\mathrm{KN}$-101 series}

After the exhaustive analysis and the interpretation of the low-stress mechanical and surface properties of functional fabrics which goes to tensile, shear, bending, compression, and surface friction were completed; we further proceed to set up the calculation works of primary hand (PHV) and total hand value (THV). This part of the paper utilizes the equations established for conventional fabrics in order to commend or reject the privilege of these types of translation equations for functional fabrics PHV and THV calculations which have been developed by Kawabata for men's winter suit [17]. He defined a primary hand values indicated the elemental fabric hand properties such as stiffness (Koshi), smoothness (Numeri), and fullness (Fukurami) and have the scale range from $0-10$, while the total hand values is an indication of the overall quality index in which a fabric intended for a particular end use and with the scale from 1-5. To achieve this, the population parameters (mean and standard deviations) of the samples were calculated and are presented in table 2. These sixteen lowstress mechanical properties were utilized to compute the primary hand values.

In order to calculate the primary hand values of the functional fabrics, we employed the equations previously developed by Kawabata and his co-workers [17] intended to use for the evaluation of the hand factors for men's winter suiting fabrics $(\mathrm{KN}-101)$ : 


\begin{tabular}{|c|c|c|c|}
\hline \multicolumn{4}{|c|}{$\begin{array}{l}\text { THE SUBSTITUTED POPULATION PARAMETERS } \\
\text { IN EQUATION KN-101 }\end{array}$} \\
\hline \multicolumn{2}{|c|}{ Mechanical parameter } & Mean value & $\begin{array}{c}\text { Standard } \\
\text { deviation } \sigma_{i}\end{array}$ \\
\hline \multirow{3}{*}{ Tensile } & $\mathrm{LT}$ & 0.950 & 0.103 \\
\hline & $\log W T$ & 0.639 & 0.090 \\
\hline & RT & 64.218 & 5.456 \\
\hline \multirow{3}{*}{ Shearing } & $\log G$ & 0.850 & 0.231 \\
\hline & $\log 2 H G$ & 1.008 & 0.370 \\
\hline & $\log 2 \mathrm{HG} 5$ & 1.175 & 0.129 \\
\hline \multirow{2}{*}{ Bending } & $\log B$ & -0.463 & 0.367 \\
\hline & $\log 2 \mathrm{HB}$ & -0.479 & 0.335 \\
\hline \multirow{3}{*}{ Compression } & LC & 0.364 & 0.038 \\
\hline & $\log W C$ & -0.503 & 0.132 \\
\hline & $\mathrm{RC}$ & 48.660 & 5.471 \\
\hline Thickness & $\log T$ & -0.175 & 0.054 \\
\hline Weight & LogW & 1.287 & 0.058 \\
\hline \multirow{3}{*}{$\begin{array}{l}\text { Surface } \\
\text { friction }\end{array}$} & MIU & 0.240 & 0.046 \\
\hline & LogMMD & -1.147 & 0.026 \\
\hline & $\log S M D$ & 0.822 & 0.033 \\
\hline
\end{tabular}

$$
Y_{k}=C_{0}+\sum_{i=1}^{16} C_{i} \frac{X_{i}-\bar{X}}{\sigma_{i}}
$$

where $Y_{k}$ is primary hand values $(k=1,2,3)$ for men's winter suit, 1 - KOSHI, 2 - NUMERI and 3 FUKURAMI, $X_{i}$ - the $i^{\text {th }}$ low-stress mechanical properties or its logarithmic values $(i=1,2,3 \ldots .16)$,

$\mathrm{x}$ and $\sigma_{i}$ are the mean $\&$ the standard deviation of the $i^{\text {th }}$ low-stress mechanical properties and $C_{0}$ and $C_{i}$ are coefficients of constants (for men's winter suit) as developed by Kawabata.

The definitions of the primary hand values are as follows [17]:

- KOSHI (stiffness); a sensation associated with bending stiffness. It is the rigidity of a fabric-the extent to which it resists bending deformation in response to the applied bending force. It is the opposite of being flexible or pliable.

- NUMERI (smoothness); a mixing sensation which derives from smooth, flexible, and soft feeling. Free from projections or unevenness of the surface. It is the direct opposite of roughness.

- FUKURAMI (swelling/softness); it is the extra word for fullness and softness or it is the feeling of being compressible. Or a combined sensation comes from bulky rich and well-formed sensation. Springy property in compression and the thickness accompanied with a warm feeling.

To calculate the primary hand values, we only swapped the mean and the standard deviations of the functional fabrics; the constants used were the

Relationship between the experimental, subjective, and calculated hand factors

After calculating the primary hand and total hand values of the functional fabrics, it is necessary to observe if the translation equations can be implemented to predict the comfort of the functional fabrics. Figure 4 displays the experimental (E) (obtained by KES) and calculated (C) primary hand values of each fabrics using translation equation $\mathrm{KN}-101$. The 


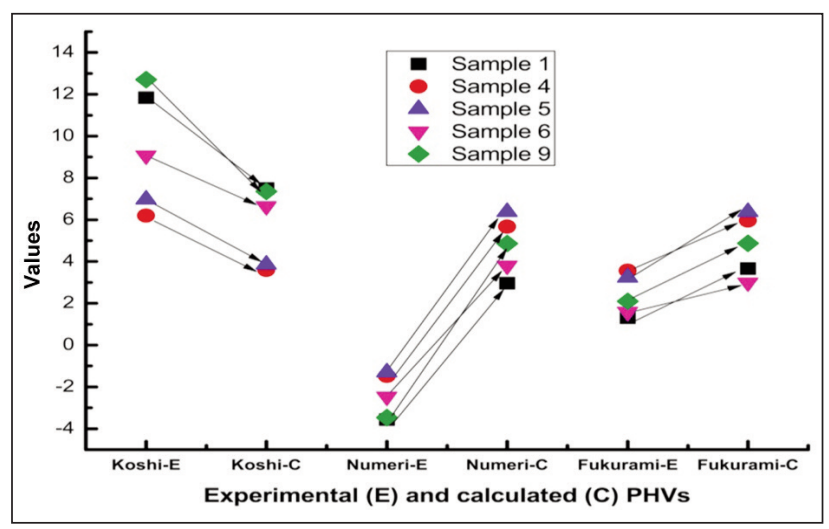

Fig. 4. The experimental $(E)$ and calculated $(C)$ primary hand values of the functional fabrics. The big variation occurred between the experimental and the calculated values of NUMERI

experimental values of NUMERI fall out on the negative axis. Experimental (E) values are the one obtained using KES instrument; calculated $(C)$ values are that obtained when using the Kawabata translation equation ( $\mathrm{KN}-101)$.

The wearable e-textile samples were intended to be used for producing men's suiting fabrics. For this classification, as noted in the figure, the deviations are in the acceptable range in the sample occurred in terms of their experimental and calculated values of the primary hand values. This was demonstrated by calculating the error values. The error values are $\sim 3.41, \sim 6.60$, and $\sim 2.39$ for Koshi, Numeri, and Fukurami, respectively. These errors are within the standard deviations (SD) of the experiments for which SD of 9.71, 12.25, and 1.94 were observed for Koshi, Numeri, and Fukurami, respectively. However, when samples are treated individually, a difference can be noted between the experimental and calculated values. For instance, sample 1 yielded an experimental Koshi value of 11.84 while the same sample yielded minimum Koshi calculated value of 7.49 which actually means the stiffness value reduced by $\sim 36.7 \%$. On the other hand, for the experimental values, for instance, the Koshi (stiffness) values of sample 9 and 1 were very high with a value of 12.71 and 11.84, respectively. Also deserve mentioning the lowest (outstanding) value, which is 6.19 for sample 4 . The Fukurami (softness) value of sample 4 was 3.56 while to that of sample 1 was 1.31 . This means sample 1 found to be the least of the other samples in terms of the softness property. The calculated primary hand values of all samples showed the same tendency to that of the experimental values. These experimental and calculated data showed that sample 4 was very qualified with properties having superior flexibility and softness for winter men's apparel suit production when compared to other samples.

For each sample, the correlation coefficients between the calculated and experimental primary hand values were established and the results are illustrated in table 5. The Pearson correlation between the calculated primary hand and the experimental values figuring out that a strong correlation existed between the hand values.

As revealed in the table, except a few results, most correlations are significant at 0.001 confidence level. This result confirmed that Kawabata's translation equation $(\mathrm{KN}-101)$ can be used as genuinely to calculate the primary hand values of the functional fabrics from low-stress mechanical properties. However, the correlation need not necessarily help whether all the data are approximately equal or not. This is because the correlation coefficient only understands the magnitude of the primary hand values. For the reason, it does not take into consideration the negative values of the primary hand when correlation coefficients computed. Therefore, it could be better to

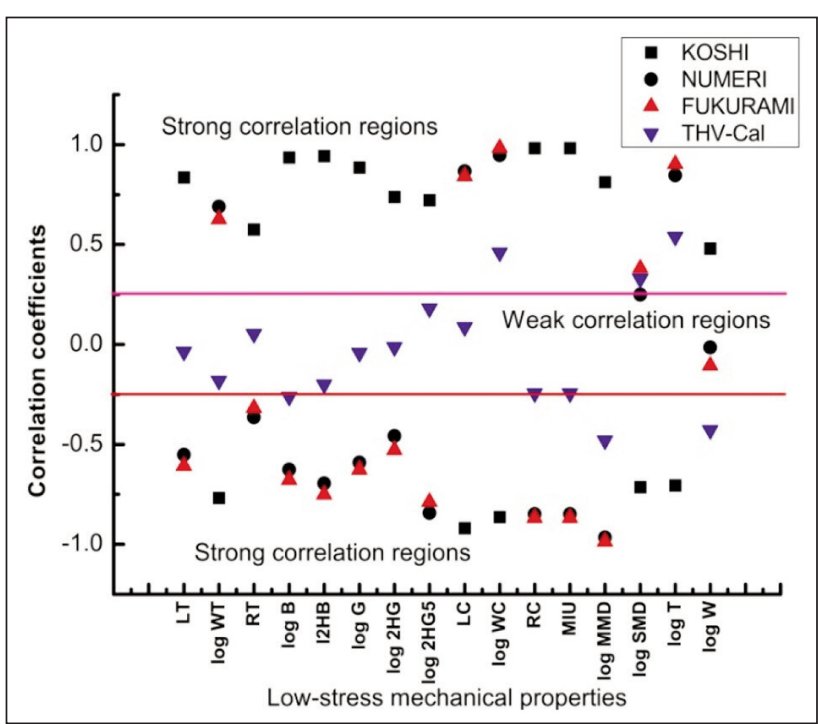

Fig. 5. The correlation coefficients between the low-stress mechanical properties and the calculated primary; total hand values of the functional fabric
Table 5

\begin{tabular}{|c|c|c|c|c|c|}
\hline \multicolumn{7}{|c|}{ THE CORRELATION COEFFICIENTS BETWEEN EXPERIMENTAL AND } \\
\hline PHV & Koshi $_{(\mathrm{E})}$ & Numeri $_{(\mathrm{E})}$ & Fukurami $_{(\mathrm{E})}$ & Koshi $_{(\mathrm{c})}$ & Numeri $_{(\mathrm{c})}$ \\
\hline Numeri $_{(\mathrm{E})}$ & -0.977 & - & - & - & - \\
\hline Fukurami $_{(\mathrm{E})}$ & 0.006 & 0.128 & - & - & - \\
\hline Koshi $_{(\mathrm{c})}$ & 0.943 & -0.963 & -0.254 & - & - \\
\hline Numeri $_{(\mathrm{c})}$ & -0.957 & 0.971 & 0.005 & -0.954 & - \\
\hline Fukurami $_{(\mathrm{c})}$ & -0.703 & 0.805 & 0.621 & -0.888 & 0.777 \\
\hline
\end{tabular}

investigate the meaning of the primary hand values in both axes and take a judge up on it.

In order to further explore the relationship between the calculated hand factors and the mechanical properties measured by Kawabata's evaluation system, the correlation coefficients were calculated and the results are shown in figure 5 . We assumed a correlation coefficient below 0.25 as a 
weak relationship and the result shows that most correlations with THV-Cal are under low regions.

The result is figuring out that, there existed a strong correlation amongst the calculated hand factors and the low-stress mechanical properties up to 0.99. This is an authentic indication of the prediction performances of the translation equations of $\mathrm{KN}$-series for the functional fabric which swayed to be served the same and is in a reliable range. Furthermore, to evaluate the prediction performances of the translation equations to the quality of the functional fabrics, the mean square errors were calculated which could enable to validate its trustworthy. We computed the predictive mean square error (MSE) between the subjective total hand value and the calculated THV using the following equation:

$$
M S E=\frac{1}{n} \sum_{i=1}^{n}\left(Y_{i}-\bar{Y}_{i}\right)^{2}
$$

where $Y_{i}$ is the experimental THV from KES-F \& actual THV given by the panel of experts, $\bar{Y}_{i}$ - the predicted THV using equations $\mathrm{KN}-301$ and $n-$ the number of samples taken.

The equation can help to show whether calculated mean square errors are within the standard deviations of each product which is a variation of the experiment or not. This verifies that $\mathrm{KN}$-equation series developed to evaluate the hand of the men's suiting fabric may possibly be used to predict the tactile comfort of the functional fabrics.

Furthermore, the frequently used measure of the differences between the hand factors predicted by the mechanical parameters and subjective total hand values given by the experts could be better explained by the root mean square error (RMSE):

$$
R M S E=\sqrt{\frac{1}{n}} \sum_{i=1}^{n}\left(Y_{i}-\bar{Y}_{i}\right)^{2}
$$

The tabulated standard deviation of the differences between the predicted and the total hand values of the fabrics is $\sim 0.78$ and the RMSE between the predicted and the rated total hand values found to be $\sim 0.66$. This shows that the root mean square error is within the standard deviation values. This result further confirmed that the prediction performance of the $\mathrm{KN}-301$ equation on the total hand values of the functional fabric using the mechanical parameters obtained by the Kawabata's evaluation system was at an acceptable range and ensured a good agreement to the human perception. While the calculated standard deviation of the differences between the experimental (KES-F) and the predicted THV was found to be $\sim 0.63$ and the RMSE between these two values found to be $\sim 1.32$ which is not within the range of standard deviation (the variation of the experiment). This certified that the experimental THV showed rare discrepancies to that of the predicted value. This intention might be more investigated using large datasets.

To define the relationship between the hand values, we computed the correlation coefficients amongst the
THV measured by the Kawabata's evaluation systems (THV-KES), calculated using Kawabata's translation equation (KES-Cal), and given by the panel of experts (KES-Sub). Table 6 shows the THV obtained using subjective evaluation.

Table 6

\begin{tabular}{|c|c|c|}
\hline \multicolumn{3}{|c|}{ THE TOTAL HAND VALUES AS RATED BY SUBJECTS } \\
\hline Sample Code & THV-Sub & STD \\
\hline 1 & 2.25 & 0.866 \\
\hline 4 & 3.15 & 0.782 \\
\hline 5 & 4.50 & 0.333 \\
\hline 6 & 2.90 & 0.527 \\
\hline 9 & 2.70 & 0.882 \\
\hline
\end{tabular}

Table 7 illustrates the correlation coefficient results between the total hand values obtained using three different mechanisms.

Table 7

RELATIONSHIPS BETWEEN THV-KES, THV-CAL AND THV-SUB

\begin{tabular}{|c|c|c|c|}
\hline THV & THV-KES & THV-Cal & THV-Sub \\
\hline THV-KES & 1 & - & - \\
\hline THV-Cal & -0.016 & 1 & - \\
\hline THV-Sub & 0.727 & 0.339 & 1 \\
\hline
\end{tabular}

The correlation coefficient results declared experimental (THV-KES) and subjectively obtained (THVSub) total hand values attain the highest relationship (at 0.01 confidence level). The calculated and subjectively obtained total hand values are significant at 0.05 confidence level. While the experimental and calculated total hand values showed a weak relationship by attaining a coefficient of correlation $\sim-0.016$. This result confirmed that both subjective evaluation and objective measurement of the mechanical properties can be simultaneously applied to evaluate the comfort of functional fabrics. The subjective total hand value (THV-Sub) has a positive correlation between THV-Cal and THV-KES while it recorded a strong correlation coefficient $(\sim 0.727)$ to that of THV-KES. This result effectively determined that the perception of the human subjects can replace the experimental measurement of the THV using KES. However, the correlation coefficient is not always correct for evaluating the certainty; this is due to the range of the hand values of the samples examined influences remarkably on the correlation coefficients. To support this, the T-test for the two-sample for variance was computed and illustrated in figure 6 .

As showed in figure 6, T-test re-approved the correlation coefficient result. This is because the F-critical one-one-tail value is greater than the $F$-value between THV-Cal and THV-KES while they build a 


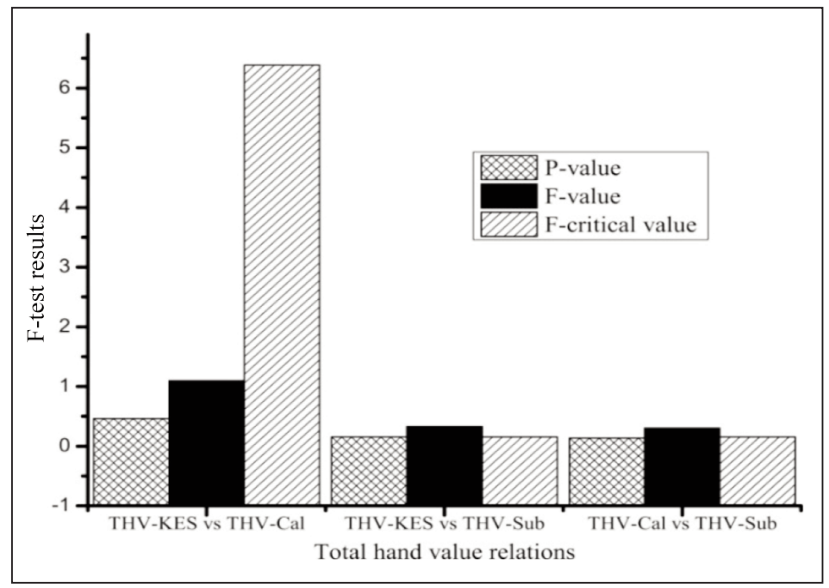

Fig. 6. T-test for two-sample variances for the hand values of experimental calculated and subjectively obtained total hand values of the sample

weak correlation coefficient $(\sim-0.016)$ between them. If the F-critical value is larger than that of the F-value, two samples showed different values in their variance. That means the null hypothesis (two means are equal statistically) will not be considered. The rest, statistically, there showed no big difference.

\section{CONCLUSIONS}

A pre-requisite for the prediction of primary and total hand values of the functional fabric using Kawabata's translation equation is to define the effect of functional finishing using polymers on the fabric's hand. The investigation in this work shows that there exists a change in the mechanical properties of the functional fabrics due to the utilization of different finishing types and parameters. The prediction performance of Kawabata's translations equations to the total hand value was in a satisfactory range as the root mean square error $(\sim 0.66)$ is within the range of the standard deviation $(\sim 0.78)$ of the differences between the calculated total hand value and the total hand value given by human experts. The relationship between the calculated primary hand values to the low-stress mechanical properties of the functional fabric found to be strong and attains up to a correlation coefficient up to $\sim 0.99$. While the relationship between the mechanical properties and the calculated THV found to be medium in which the maximum correlation coefficient was $\sim 0.54$. These results give the evidence that the primary hand values are highly dependent on the mechanical properties while the total hand values might not depend only on the mechanical properties; other factors should be investigated. The calculated and experimental primary hand values attain a correlation coefficient up to $\sim 0.98$ showing that the primary hand values of the functional fabrics can be explained using Kawabata's translation equations.

\section{ACKNOWLEDGEMENTS}

This work was financially supported by Erasmus Mundus Joint Doctorate Programme SMDTex-Sustainable Management and Design for Textile (Grant No. n_20151594/001-001-EMJD). The authors would like to acknowledge The Faculty of Textile Engineering, Technical University of Liberec, Czech Republic, for conducting the Kawabata Evaluation for our samples.

\section{REFERENCES}

[1] Lee, J., Kwon, H., Seo, J., Shin, S., Koo, J.H., Pang, C., Son, S., Kim, J.H., Jang, Y.H., Kim, D.E., Lee, T., Conductive fiber-based ultrasensitive textile pressure sensor for wearable electronics, In: Adv. Mater., 2015, 27, 2433-2439

[2] Zhang, M., Wang, C., Wang, H., Jian, M., Hao, X., Zhang, Y., Carbonized Cotton Fabric for High-Performance Wearable Strain Sensors, In: Adv. Funct. Mater., 2017, 27, 1-7

[3] Cochrane, C., Koncar, V., Lewandowski, M., Dufour, C., Design and development of a flexible strain sensor for textile structures based on a conductive polymer composite, In: Sensors, 2007, 7, 473-492

[4] Seyedin, S., Razal, J.M., Innis, P.C., Jeiranikhameneh, A., Beirne, S., Wallace, G.G., Knitted Strain Sensor Textiles of Highly Conductive All-Polymeric Fibers, In: ACS Appl. Mater. Interfaces, 2015, 7, 21150-21158

[5] Wen, Z., Yeh, M.H., Guo, H., Wang, J., Zi, Y., Xu, W., Deng, J., Zhu, L., Wang, X., Hu, C., Zhu, L., Sun, X., Wang, Z.L., Self-powered textile for Wearable electronics by hybridizing fiber-shaped nanogenerators, solar cells, and supercapacitors, In: Sci. Adv., 2016, 2.e1600097

[6] Tadesse M.G., Loghin, C., Chen, Y., Wang, L., Catalin, D., Nierstrasz, V., Effect of liquid immersion of PEDOT: PSScoated polyester fabric on surface resistance and wettability, In: Smart Mater. Struct., 2017, 26.065016

[7] Tadesse, M.G., Dumitrescu, D., Loghin, C., Chen, Y., Wang, L., Nierstrasz, V., 3D Printing of NinjaFlex Filament onto PEDOT:PSS-Coated Textile Fabrics for Electroluminescence Applications, In:J. Electron. Mater., 2018, 47, 2082-2092

[8] Cardello, A.V, Schutz, H.G., Predicting the Handle and Comfort of Military Clothing Fabrics from Sensory and Instrumental Data: Development and Application of New Psychophysical Methods, In: Text. Res. J., 2003, 73, 221-237

[9] Das, A., Alagirusamy, R., Improving tactile comfort in fabrics and clothing. In Improving Clothing Comfort, Song G. Ed., Woodhead publishing: Oxford,UK, 2011,216-244

[10] Nayak, R.K., Punj, S.K., Chatterjeé, K.N., Behera, B.K., Comfort properties of suiting fabrics, In: Indian J. Fibre Text. Res., 2009, 34, 122-128

[11] Raj, S., Sreenivasan, S., Total Wear Comfort Index as an Objective Parameter for Characterization of Overall Wearability of Cotton Fabrics, In:J. Eng. Fiber. Fabr., 2009, 4, 29-41 
[12] Mahar, T.J., Postle, R., Measuring and Interpreting Low-Stress Fabric Mechanical and Surface Properties: Part IV: Subjective Evaluation of Fabric Handle, In: Text. Res. J., 1989, 59, 721-733

[13] Mahar, T.J., Postle, R., Measuring and Interpreting Low-Stress Fabric Mechanical and Surface Properties: Part II: Applications to Finishing, Drycleaning, and Photodegredation of Wool Fabrics, In: Text. Res. J., 1989, 59,357-368

[14] Mahar, T.J., Wheelwright, P., Dhingra, R.C., Postle, R., Measuring and Interpreting Fabric Low Stress Mechanical and Surface Properties: Part V: Fabric Handle Attributes and Quality Descriptors, In: Text. Res. J., 1990, 60, 7-17

[15] Mahar, T.J., Postle, R., Measuring and Interpreting Low-Stress Fabric Mechanical and Surface Properties:Part III: Optimization of Fabric Properties for Men's. Suiting Materials, In: Text. Res. J., 1989, 59, 448-459

[16] Behera, B.K., Comfort and handle behaviour of linen-blended fabrics, In: Autex Res. J., 2007, 7, 32-47

[17] Kawabata, S., The Standardization and Analysis of Hand Evaluation. In Effect of Mechanical and Physical Properties on Fabric Hand, 2nd ed., M.H. Behery Ed., Woodhead Publishing: Cambridge, England, 2005, 389-442

[18] Mitsu, M., Masahiko, K., Objective Evaluation of Hand for Futon Cloth, In: J. Text. Mach. Soc. Japan., 1996, 42, 23-35

[19] Singh, J.P., Behera, B.K., Matsudaira, M., Objective evaluation of terry fabric hand, In: J. Text. Inst., 2014,105, 467-476

[20] Niwa, M., Inoue, M., Kawabata, S., Objective evaluation of the handle of blankets, In: Text. Res. J., 2001, 71, 701-710

[21] Kawabata, S., Niwa, M., Wang, F., Objective Hand Measurement of Nonwoven Fabrics: Part I : Development of the Equations, In: Text. Res. J., 1994, 64, 597-610

[22] Yokura, H., Kohono, S., Iwasaki, M., Objective hand measurment of toilet paper, In: J. Text. Eng., 2004, 50, 1-5

[23] Seipel, S., Yu, J., Periyasamy, A.P., Viková, M., Vik, M., Nierstrasz, V.A., Inkjet printing and UV-LED curing of photochromic dyes for functional and smart textile applications, In: RSC Adv., 2018, 8, 28395-28404

[24] Tadesse, M.G., Harpa, R., Chen, Y., Wang, L., Nierstrasz, V., Loghin, C., Assessing the comfort of functional fabrics for smart clothing using subjective evaluation, In: J. Ind. Text., 2018, doi:10.117/152808371874906.

[25] Ryan, J.D., Mengistie, D.A., Gabrielsson, R., Lund, A., Müller, C., Machine-Washable PEDOT:PSS Dyed Silk Yarns for Electronic Textiles, In: ACS Appl. Mater. Interfaces., 2017, 9, 9045-9050

Author:

MELKIE G.TADESSE ${ }^{1}$, EMIL-CONSTANTIN LOGHIN², VINCENT NIERSTRASZ³ ${ }^{3}$ MARIA-CARMEN LOGHIN²

${ }^{1}$ Bahir Dar University, Ethiopian Institutes of Textile and Fashion Technology, 608 Bahir Dar, Ethiopia

${ }^{2}$ Gheorghe Asachi Technical University of lasi, Faculty of Industrial Design and Business Management, Knitting and Clothing Engineering Department, Bld. D. Mangeron no. 29, 700050, lași, Romania

3University of Boras, Swedish School of Textiles, Department of Materials Technology, 50190, Boras, Sweden

Corresponding author:

LOGHIN EMIL-CONSTANTIN

e-mail: eloghin@tuiasi.ro 